\title{
Impact of ambulatory palliative care on symptoms and service outcomes in cancer patients: a retrospective cohort study
}

\author{
Rajvi Shah ${ }^{1,2^{*}}$ (D), Ekavi N. Georgousopoulou², Ziad Al-Rubaie ${ }^{2}$, Merlina Sulistio ${ }^{1,2,3}$, Hoong Tee ${ }^{1}$,
} Adelaide Melia' and Natasha Michael ${ }^{1,2,3}$

\begin{abstract}
Background: The integration of palliative care into routine cancer care has allowed for improved symptom control, relationship building and goal setting for patients and families. This study aimed to assess the efficacy of an ambulatory palliative care clinic on improving symptom burden and service outcomes for patients with cancer.

Methods: A retrospective review of data of cancer patients who attended an ambulatory care clinic and completed the Symptom Assessment Scale between January 2015 and December 2019. We classified moderate to severe symptoms as clinically significant. Clinically meaningful improvement in symptoms (excluding pain) was defined by $a \geq 1$-point reduction from baseline and pain treatment response was defined as $a \geq 2$-point or $\geq 30 \%$ reduction from baseline.

Results: A total of 249 patients met the inclusion criteria. The most common cancer diagnosis was gastrointestinal (32\%) and the median time between the initial and follow-up clinic was 4 weeks. The prevalence of clinically significant symptoms at baseline varied from $28 \%$ for nausea to $88 \%$ for fatigue, with $23 \%$ of the cohort requiring acute admission due to unstable physical/psychosocial symptoms. There was significant improvement noted in sleep $(p<0.001)$, pain $(p=0.002)$, well being $(p<0.001)$, and overall symptom composite scores $(p=0.028)$. Despite $18-28 \%$ of patients achieving clinically meaningful symptom improvement, $18-66.3 \%$ of those with moderate to severe symptoms at baseline continued to have clinically significant symptoms on follow-up. A third of patients had opioid and/or adjuvant analgesic initiated/titrated, with 39\% educated on pain management. Goals of care (31\%), insight (28\%) and psychosocial/existential issues (27\%) were commonly explored.
\end{abstract}

Conclusions: This study highlights the burden of symptoms in a cohort of ambulatory palliative care patients and the opportunity such services can provide for education, psychosocial care and future planning. Additionally routine screening of cohorts of oncology patients using validated scales may identify patients who would benefit from early ambulatory palliative care.

Keywords: Cancer pain, Cancer symptom, Outpatient, Ambulatory, Palliative care, End-of-life care, Clinic

*Correspondence: rajvishah06@gmail.com

1 Supportive, Psychosocial and Palliative Care Research Department,

Cabrini Health, 154 Wattletree Road, Malvern, VIC 3144, Australia

Full list of author information is available at the end of the article

\section{Introduction}

Despite advances in cancer treatment and its subsequent impact on prognosis and trajectory, unrelieved symptoms continue to have a debilitating effect on patients and families, evoking much suffering and impeding the attainment of an acceptable quality of life (QOL) [1,2]. 
Cancer symptoms commonly present as clusters, vacillate in their severity and may be attributed to disease or treatment and may continue into survivorship [3, 4]. Symptoms include, but are not limited to, pain, anorexia, fatigue, shortness of breath, nausea, constipation, and anxiety, with a prevalence ranging from 50 to $84 \%[5,6]$.

The emergence of palliative care as a mainstream specialty and integration of early palliative care into cancer care has allowed for the early identification, assessment and treatment of pain and other symptoms [7]. Multiple international studies have highlighted that early palliative care, when provided alongside standard oncological care, leads to improved patient outcomes and clinically meaningful improvements in QOL and survival [8]. The expansion of cancer care in the ambulatory setting has supported the concurrent development of ambulatory palliative care clinics $[9,10]$. Such clinics allow for the collaborative integration of palliative care into routine cancer care to assist with symptom control, relationship building, continuity of care and goal setting $[11,12]$. Guidelines in Australia suggest that ambulatory palliative care services should be provided in ambulatory clinics or specialist rooms but with no specific articulations for best practice in the Australian cancer setting [13].

An international Delphi study recommends 11 major criteria for referral to ambulatory palliative care: severe physical and emotional symptoms, request for hastened death, spiritual or existential crisis, assistance with decision making or care planning, patient request for a referral, delirium, spinal cord compression, brain or leptomeningeal metastases, within 3 months of an advanced cancer diagnosis for patients with a median survival of 1 year or less, and progressive disease despite secondline therapy [14]. Additionally, ambulatory palliative care referrals should be triggered by symptom screening in conjunction with clinician-based referrals [15].

International studies assessing the efficacy of ambulatory palliative care on symptom burden and patient satisfaction with care commonly focused on measurable changes in patient-reported outcomes measured through multi-item symptom assessment scales [16, 17]. A commonly used scale, the Edmonton Symptom Assessment Scale (ESAS), measures 11 common cancer symptoms on a numerical rating scale (NRS) $[18,19]$. A phase II Canadian study of 88 cancer patients attending ambulatory palliative care demonstrated significant improvements in pain, fatigue, nausea, anxiety, dyspnoea and insomnia $(p \leq 0.0001)$, as well as depression, drowsiness, and constipation $(p \leq 0.002)$ at 1-month follow-up [11]. A subsequent retrospective longitudinal study in the United States of 1612 cancer patients with moderate to severe symptoms at baseline (NRS $\geq 4$ ) demonstrated statistically significant improvement in all ESAS symptom domains between the initial review and subsequent follow up $(p<0.001)$, with $45 \%(p<0.001)$ demonstrating a two-point difference or $30 \%$ reduction in pain intensity on NRS $[4,20]$. A further study of 182 patients with stage IV cancer reviewed in an ambulatory palliative care clinic in Jordan found improvement in pain $(p=0.004)$ and sleep disturbance $(p=0.007)$ regardless of baseline symptom intensity score, with statistically significant improvement in all ESAS domains for patients with moderate to severe symptoms $(\mathrm{NRS} \geq 4)(p \leq 0.003)[5]$.

As part of our organisation's integrated specialist palliative care service (inpatient, community, consult and ambulatory), an ambulatory palliative care clinic, known as the Supportive Care Clinic (SCC), was established in 2015. The aim of this study was to retrospectively assess the impact of the SCC on clinical and service outcomes, including assessing for improvement in symptom burden, clinical interventions implemented and evaluating forward referrals to other aspects of the service. To our knowledge, this is the first study to assess the impact of an ambulatory palliative care clinic in an Australian setting.

\section{Methods \\ Design}

We conducted a retrospective cohort study of all new patients presenting to the SCC between January 2015 and December 2019 in a single institution. Eligible patients were at least 18 years old, diagnosed with a solid organ or haematological malignancy of any stage and were newly assessed by a Palliative Care Physician in the ambulatory setting. Patients who had incomplete medical records or missing physician correspondence from the initial appointment were excluded from this study. The study complied with the STROBE guidelines for the reporting of observational studies. Ethics was granted by the organisation's Human Research Ethics Committee (Number: 08-18-05-20) and the study was funded by the Cabrini Foundation Quality Improvement Grant.

\section{Setting}

This study was conducted at a large not-for-profit, private health care service in Melbourne, Australia, providing acute, sub-acute and community-based care across six campuses. Specialist Palliative Care is available via an integrated service, comprising a 22-bed inpatient unit, a hospital consultation service, a community service and ambulatory Supportive Care Clinics. The Supportive Care Clinic is staffed by a specialist accredited Palliative Medicine Physician, supported by a nurse, allied health team, pharmacist and is physically located within the Haematology and Oncology Centre. All patients who 
attend the SCC complete a Symptom Assessment Scale (SAS) on arrival [21].

\section{Data sources and outcomes}

We used the hospital's administrative database to identify patients who attended the clinic during the study period. New attendees at the clinic were identified using the Medicare Benefits Schedule item number for a first review [22]. Electronic medical records of identified patients were reviewed against the remaining eligibility criteria. We gathered information on patient demographics, presence and severity of symptoms, and clinical and service outcomes following clinic review.

To assess patient-reported symptom outcomes, we used the SAS [21]. The SAS utilises an NRS (0-10), similar to the ESAS, and is used by palliative care services across Australia involved in the Palliative Care Outcomes Collaboration [23]. The SAS assesses the amount of distress caused by symptoms across 8 domains: sleep disturbance, anorexia, nausea, bowel problems, dyspnoea, fatigue, pain, and other symptoms and demonstrates strong psychometric properties of internal consistency $(\alpha=0.64-0.92)$ and reliability $(r=0.84-0.92)$ [21]. Impairments in overall mood and wellbeing/QOL were additionally assessed on an NRS (0-10). We reviewed data from the initial clinic assessment and those who attended a follow-up clinic within 8 weeks of their initial appointment.

Intensity of symptoms reported on the SAS were categorised as follows: NRS $0=$ absent, $1-3=$ mild, $4-7=$ moderate and $8-10=$ severe [21]. Clinically significant symptoms were classified as those with NRS $\geq 4$, while $a \geq 1$-point reduction in NRS defined a clinically meaningful improvement for all symptoms excluding pain [24]. For pain, we assessed pain treatment response, defined as $\geq 2$-point reduction or $\geq 30 \%$ reduction from baseline pain score [25]. A symptom composite score was calculated by summing the 8 SAS items [11]. The score was prorated as long as the participant has completed more than $50 \%$ of the SAS items with prorated scores calculated by summing the individual scores, multiplying by the number of possible items ( 8 items), and dividing by the total number of items completed [11].

Corresponding physician clinic correspondence was examined by three investigators (HT, RS, AM). We developed a standardised data collection sheet to obtain the following data: basic demographics, medication changes and their indications, referrals generated, physical, social and psycho-existential issues explored during the consultation and patient disposition after the clinic appointment. An initial pilot study was conducted to confirm the utility and appropriateness of the data collected. A third of the data was reassessed to ensure concordance in data obtained between reviewers.

\section{Statistical analysis}

Patients' socio-demographic characteristics, presence and intensity of baseline symptoms, and appointment outcomes of interest were summarised using descriptive statistics, including mean, median, frequencies and valid percentages. Where patients had a second clinic appointment, we used Paired t-test (or Wilcoxon signed rank test when appropriate) to test for changes in symptom intensity scores between the two time-points. A significance criterion of $p \leq 0.05$ was used in the analysis. Statistical analysis was performed using SPSS V.25.0 on valid data.

\section{Results}

\section{Patient characteristics}

Of 1060 patients reviewed in the SCC over the 5 years, 282 met the eligibility criteria and data from 249 patients was evaluated (Fig. 1). The baseline characteristics of the patients are summarised in Table 1 . The mean patient age at the initial clinic appointment was 68.7 years, the majority were female (53.8\%), and the most common cancer diagnosis was gastrointestinal, encompassing colorectal and pancreatic cancer $(n=80,32.1 \%)$. At the conclusion of the study period, 204 (81.9\%) of the study cohort were deceased, and the mean age at death was 69 years. The median time between the first referral to the integrated palliative care service and initial SCC appointment was 110 days, and the first referral to the service and death was 152.5 days. Over half the patients (54.9\%) died in a dedicated palliative care unit, whilst a quarter $(25.5 \%)$ died at their usual community residence.

\section{Baseline symptom intensity}

Figure 2 shows the baseline symptom prevalence categorized into absent, mild, moderate and severe subgroups. The three most common clinically significant symptoms $(\mathrm{NRS} \geq 4)$ reported were fatigue $(82.6 \%)$, pain $(68.8 \%)$ and mood (54.5\%), with close to half reporting them for anorexia (49.8\%), sleep disturbance $(49.1 \%)$ and bowel problems (48.6\%). Three-quarters of the cohort reported clinically significant impairment in their wellbeing/QOL (75.7\%). The mean baseline symptom composite score was $30.9(\mathrm{SD}=15.5)$. Figure 3 demonstrates the mean symptom composite scores stratified to primary malignant diagnosis, with the highest scores in the gynaecology (mean 41.2, $\mathrm{SD}=15.7$ ), breast (mean 39.1, $\mathrm{SD}=13.7$ ) and gastrointestinal (mean 34.5, $\mathrm{SD}=15.8$ ) cancer groups. 


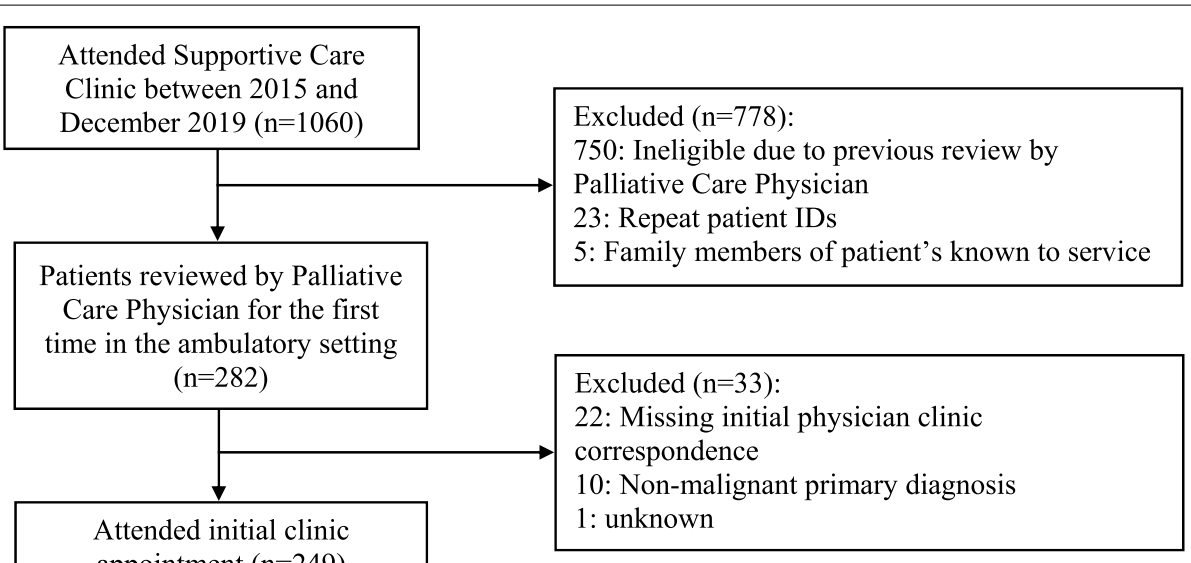

Fig. 1 Subject selection

\section{Symptom changes}

Of the 249 patients included in our study, 126 (50.6\%) attended a follow-up appointment within 8 weeks, with a median time of 4 weeks (IQR $=2.5-6.9$ ) between clinic appointments. Table 2 summarises the change in symptom scores between the initial and follow up appointments, demonstrating a statistically significant reduction in symptom intensity for sleep disturbance $(p<0.001)$, pain $(p=0.002)$, overall wellbeing $(p<0.001)$ and symptom composite score $(p=0.028)$. There was also a statistically significant worsening in $\operatorname{mood}$ score $(p=0.002)$. For patients with moderate to severe symptom scores at baseline, $18-25 \%$ of patients had a clinically significant improvement (NRS $\geq 1$ improvement for all SAS domains excluding pain, for pain NRS $\geq 2$ improvement) in their symptom intensity between the initial and follow-up clinic appointments. However, $18-67 \%$ of patients with moderate or severe symptoms at baseline continued reporting clinically significant symptoms $(\mathrm{NRS} \geq 4)$ at follow-up (Table 2).

\section{Clinical and service outcomes}

Table 3 demonstrates the clinical and service outcomes from the initial clinic appointment. A third of patients had an opioid (30.9\%) and/or an adjuvant analgesic (30.5\%) initiated or titrated in the first appointment. Additionally, patients underwent opioid rotation (11.6\%) or changes to their medications for nausea (7.6\%), bowel issues (6\%), insomnia (5.6\%) or $\operatorname{mood}(3.2 \%)$. Up to $39.4 \%$ of patients were provided with education on pain management. The most common issues explored in the clinic were goals of care (30.9\%), insight (27.7\%), psychosocial/ existential issues experienced by patients and caregivers $(27.3 \%)$ and future treatment options (26.1\%). After the initial clinic appointment, a quarter of the study cohort (23.3\%) required an urgent admission to a palliative care unit due to inadequately managed physical or psychosocial symptoms.

\section{Discussion}

This is the first Australian study to examine the prevalence of symptoms and the impact of a supportive care clinic on patient-reported and service outcomes in cancer patients. Our findings confirm the high symptom burden experienced in this cohort, with the supportive care clinic a catalyst for admission for a quarter of the patients reviewed. We were able to affirm the benefit of ambulatory interventions by significant improvements in sleep, pain, wellbeing and overall symptom composite scores on follow-up. This study adds to the growing body of literature demonstrating the need for and efficacy of ambulatory palliative care $[4,5,11,20]$. A direct comparison, however, of our study to other studies is challenging due to the heterogeneity in the palliative care service model globally, time to follow-up and differences in outcome measures. Whilst the SAS, which is widely used in an Australian palliative care context, and other symptom assessment tools, including the ESAS, rely on patient reporting of intensity on an NRS for a number of overlapping symptom domains, the relationship and congruence of these tools is unknown.

The high burden of clinically significant symptoms at baseline mirrors that shown in a previous retrospective study by Kang et al. [4]; however, we demonstrated improvement in symptoms occurred regardless of baseline symptom intensity. Whilst earlier studies in the ambulatory palliative care setting have shown a trend for mild baseline symptoms to intensify $[4,5]$, this was not evident in our study apart from worsening mood scores. 
Table 1 Patient characteristics

\begin{tabular}{|c|c|}
\hline & $n=249(\%)^{\mathrm{a}}$ \\
\hline Age at initial clinic appointment, mean in years (SD) & $68.7(12.7)$ \\
\hline \multicolumn{2}{|l|}{ Sex } \\
\hline Female & $134(53.8)$ \\
\hline Male & $115(46.1)$ \\
\hline \multicolumn{2}{|l|}{ Relationship status $(n=243)$} \\
\hline Married/Defacto & $165(67.9)$ \\
\hline Single & $29(11.9)$ \\
\hline Widowed & $32(13.1)$ \\
\hline Divorced/Separated & $17(7.0)$ \\
\hline \multicolumn{2}{|l|}{ Place of birth $(n=246)$} \\
\hline Australia/New Zealand & $180(73.2)$ \\
\hline United Kingdom/Europe & $49(19.9)$ \\
\hline Other & $17(6.9)$ \\
\hline \multicolumn{2}{|l|}{ Source of referral to clinic $(n=245)$} \\
\hline Specialist clinician & $108(44.0)$ \\
\hline Community palliative care service & $94(38.3)$ \\
\hline Palliative care team on discharge from acute hospital & $18(7.3)$ \\
\hline Palliative care team on discharge from inpatient palliative care unit & $11(4.5)$ \\
\hline General practitioner & $8(3.3)$ \\
\hline Other & $6(2.4)$ \\
\hline \multicolumn{2}{|l|}{ Primary malignant diagnosis } \\
\hline Gastrointestinal & $80(32.1)$ \\
\hline Genitourinary & $42(16.9)$ \\
\hline Lung & $32(12.9)$ \\
\hline Breast & $26(10.4)$ \\
\hline Gynaecology & $24(9.6)$ \\
\hline Haematological & $16(6.4)$ \\
\hline Skin and soft tissue & $12(4.8)$ \\
\hline Other & $17(6.8)$ \\
\hline Age at death, mean in years (SD) & $69(12.3)$ \\
\hline \multicolumn{2}{|l|}{ Place of death $(n=204)$} \\
\hline Palliative care unit & $112(54.9)$ \\
\hline Home & $52(25.5)$ \\
\hline Acute hospital & $23(11.3)$ \\
\hline Aged care facility & $17(8.3)$ \\
\hline Median time between initial clinic appointment and death in days (IQR) & $110(50.8-211)$ \\
\hline Median time between initial referral to palliative care service and death in days (IQR) & $152.5(81.8-342.5)$ \\
\hline
\end{tabular}

SD Standard deviation, IQR Inter-quartile range

a unless otherwise specified

Limited improvement in the domains of anorexia, nausea, bowels, dyspnoea and fatigue may be partly attributed to a smaller cohort size that prevented subgroup analysis for those with baseline moderate to severe symptoms. Additionally, symptom education was disproportionate in the initial clinic appointment, with $39.4 \%$ of patients receiving education on pain management, compared to $7.2 \%$ on fatigue and $4.4 \%$ on both dyspnoea and bowel management.
The American Society of Clinical Oncology Clinical Practice Guidelines for Palliative Care recommend that beyond symptom management, palliative care teams should assist with care coordination and explore insight, clarify treatment goals, assist with coping and provide education about illness and prognosis to cancer patients and their caregivers [26]. Whilst our SCC included aspects of this recommended practice, with up to $30 \%$ of patients having insight explored, appointment length 

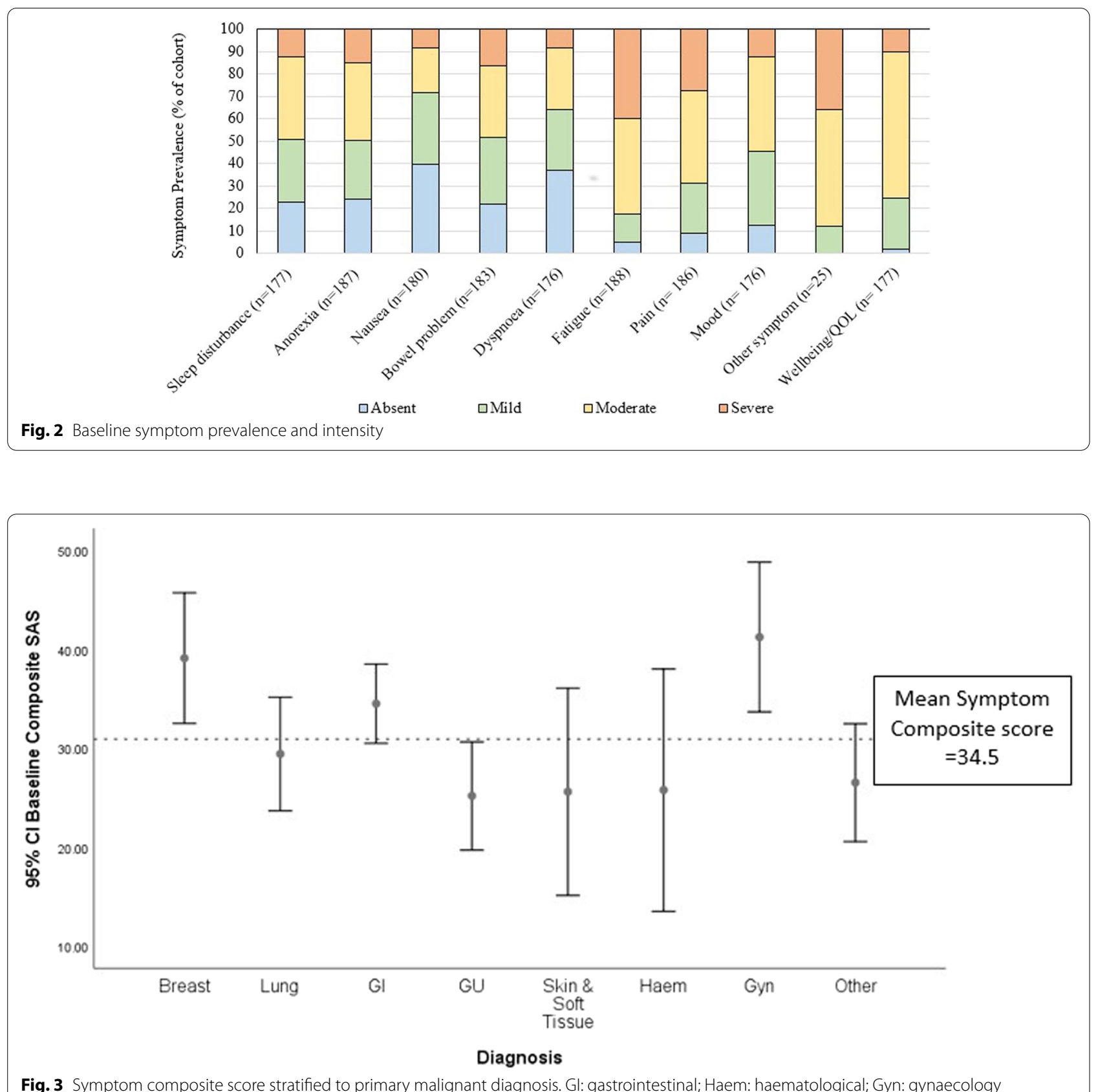

related time constraints prevented a more comprehensive approach. As time has been described as a significant factor towards the success of palliative care, we support the recommendation for an increased patient-contact time by an extra hour a month for subsequent follow-up appointments via a face-to-face or telehealth consultation [26]. This will enable a focus on improving patient education as an essential component of the ambulatory palliative care service [27].
There are two further findings of note. Compared to previously published Australian data suggesting that cancer patients have accessed specialist palliative care for a median of 30 days (IQR 10-81 days) and community palliative care services for 62 days (IQR 26-137) before death [28], our study demonstrated that patients in our cohort accessed services for longer periods (median of 152.5 days, IQR 81.8-342.5). Though the median time from first referral to the integrated palliative care service to initial SCC appointment was 110 days, in the interim, 
Table 2 Change in SAS score

\begin{tabular}{|c|c|c|c|c|c|c|c|c|}
\hline & \multicolumn{2}{|c|}{ Baseline SAS Score } & \multicolumn{2}{|c|}{ Follow-up SAS score } & \multirow[t]{2}{*}{$p$-value } & \multicolumn{3}{|c|}{ Baseline NRS $\geq 4$} \\
\hline & $n(\%)$ & Median (IQR) & $n(\%)$ & Median (IQR) & & $n(\%)$ & $\begin{array}{l}\mathrm{n}(\%) \text { with } \\
\mathrm{NRS} \geq 1 \text {-point } \\
\text { improvement }\end{array}$ & $\begin{array}{l}n(\%) \text { with } \\
\text { NRS } \geq 4 \text { at first } \\
\text { follow-up }\end{array}$ \\
\hline Sleep disturbance & $177(71.1)$ & $3(1,6)$ & $76(30.5)$ & $2(0,5)$ & $<0.001$ & $84(49.1)$ & $21(24.1)$ & $18(39.1)$ \\
\hline Anorexia & $187(75.1)$ & $3(1,7)$ & $74(29.7)$ & $2(0,5)$ & 0.720 & $93(49.8)$ & $22(21.5)$ & $16(32.7)$ \\
\hline Nausea & $180(72.3)$ & $1(0,5)$ & $75(30.1)$ & $1(0,3)$ & 0.137 & $51(28.3)$ & $14(27.5)$ & $7(30.4)$ \\
\hline Bowel & $183(73.5)$ & $3(1,7)$ & $75(30.1)$ & $3(1,5)$ & 0.062 & 89 (48.6) & 34 (21.9) & $25(53.1)$ \\
\hline Dyspnoea & $176(70.7)$ & $2(0,5)$ & $75(30.1)$ & $2(0,4)$ & 0.580 & $63(35.8)$ & $14(22.2)$ & $11(44.0)$ \\
\hline Fatigue & $188(75.5)$ & $7(5,8)$ & $75(30.1)$ & $3(1,5)$ & 0.059 & $155(82.6)$ & 34 (21.9) & $53(66.3)$ \\
\hline Pain $^{\mathrm{a}}$ & $186(74.7)$ & $6(3,8)$ & $76(30.5)$ & $2(0,4)$ & 0.002 & $128(68.8)$ & $28(21.9)$ & $42(52.5)$ \\
\hline Mood & $176(70.1)$ & $4(1,6)$ & $71(28.5)$ & $6(4,7)$ & 0.002 & $96(54.5)$ & $26(27.1)$ & $26(48.1)$ \\
\hline Other & $25(10.1)$ & $7(6,9)$ & $12(4.8)$ & $5(1,7)$ & 0.021 & $22(88)$ & $4(18.2)$ & $2(18.2)$ \\
\hline Wellbeing/QOL & $177(71.1)$ & $5(4,7)$ & $72(28.9)$ & $2(0,5)$ & $<0.001$ & $134(75.7)$ & $356(26.1)$ & 49 (63.6) \\
\hline $\begin{array}{l}\text { Symptom compos- } \\
\text { ite score, mean (SD) }\end{array}$ & $183(73.5)$ & 30.9 (15.5) & 75 (30.1) & $25.9(13.4)$ & 0.028 & & & \\
\hline
\end{tabular}

QOL Quality of life, SD Standard deviation

${ }^{\text {a }}$ For pain cut-off of NRS $\geq 2$ improvement used; $p$-values derived from Wilcoxon signed rank test

patients would have accessed the service through contact with the inpatient consultation team or community nursing team. This reflects the transformation of the palliative care service over several years to one of early integration [29], allowing for earlier targeting of symptoms and provision of support. Secondly, using the symptom composite score as a surrogate marker for overall symptom burden, gynaecological cancer patients had the highest symptom composite scores despite representing less than $10 \%$ of the cohort. This finding is consistent with studies showing high symptom burden in this group regardless of stage and site of cancer, with younger age, ongoing treatment and history of chronic pain, depression or anxiety being predictors [30]. Likewise, patients with breast cancer, who reported the second highest symptom composite score in our cohort, are more likely to report higher levels of symptom burden with lower coping capacity and emotional distress [31]. These factors support recommendations of routine screening of targeted patients occurring concurrently with referrals based on clinician discretion [14] and may help to identify areas for future study in our institution's cancer population who are currently not being seen in the SCC.

Our study had several limitations. Firstly, our study cohort was subject to bias. There was a high prevalence of gastrointestinal cancers in our cohort, encompassing colorectal and pancreatic cancer, and a low prevalence of skin cancers, likely secondary to our institution's reputation as a leading colorectal surgery centre which contributed to selection bias. Additionally, of the 1060 patients seen by the service in 5 years, only 249 patients met the eligibility criteria and were evaluated, adding a further bias to the study. Secondly, given the integrated palliative care service model, which encompasses inpatient, community, consult and ambulatory services, our patients may have had access to symptom management and interventions between clinic consultations via the community and acute sector consultation and inpatient palliative care teams. Thus, it is difficult to directly attribute the changes in patient-reported outcomes to the initial SCC appointment. Thirdly, as only half of our initial cohort completed follow up SAS scores, the change in patient-report symptom scores may be underrepresented. This may explain the large proportion of patients (18-66.6\%) who had moderate to severe symptoms at baseline that continued to have moderate to severe symptoms at follow-up. Finally, our follow-up time between appointments of 4 weeks is longer than the 15-21 days seen in earlier studies $[4,5,20]$. We hypothesise that this prolonged time to follow-up, due to natural progression and clinical deterioration in advanced malignancy, may have contributed to the high proportion of our patients who still had clinically significant symptoms, particularly fatigue, at follow-up.

\section{Conclusion}

In summary, this study highlights the high burden of clinically significant symptoms and the need for effective symptom management programs in the ambulatory setting for patients with cancer. It also demonstrates the opportunity such services provide to enable patient education, psychosocial care and future planning. 
Table 3 Clinical and Service Outcomes

\begin{tabular}{|c|c|}
\hline & $n(\%)$ \\
\hline \multicolumn{2}{|l|}{ Medication changes } \\
\hline Opioid initiation/titration & $77(30.9)$ \\
\hline Adjuvant analgesic initiation/titration & $76(30.5)$ \\
\hline Opioid conversion/rotation & $29(11.6)$ \\
\hline Anti-emetic initiation/titration/conversion & $19(7.6)$ \\
\hline Changes to bowel regimen & $15(6.0)$ \\
\hline Medication Management of insomnia & $14(5.6)$ \\
\hline Commencement/Changes of anxiolytic/anti-depressant & $8(3.2)$ \\
\hline Other medication change $\mathrm{e}^{\mathrm{a}}$ & $37(14.9)$ \\
\hline \multicolumn{2}{|l|}{ Referrals to } \\
\hline Allied health/ancillary support & $29(11.6)$ \\
\hline Interventional radiology and radiological investigations & $24(9.6)$ \\
\hline Psychiatry/psychological services & $18(7.2)$ \\
\hline Oncology/haematology/radiation oncology & $9(3.6)$ \\
\hline Other medical or surgical & $16(6.4)$ \\
\hline \multicolumn{2}{|l|}{ Symptom education } \\
\hline Pain management & $98(39.4)$ \\
\hline Gastrointestinal symptom and bowel management & $22(8.8)$ \\
\hline Fatigue management & $18(7.2)$ \\
\hline Dyspnoea management & $11(4.4)$ \\
\hline Diet and nutrition management & $10(4.0)$ \\
\hline Mood and insomnia management & $13(5.2)$ \\
\hline Other symptom management & $16(6.4)$ \\
\hline \multicolumn{2}{|l|}{ Issues explored/discussed } \\
\hline Establishing goals of care & $77(30.9)$ \\
\hline Insight & $69(27.7)$ \\
\hline Patient and caregiver psychosocial/existential distress & $68(27.3)$ \\
\hline Future treatment options & $65(26.1)$ \\
\hline Prognosis & $53(21.3)$ \\
\hline Preferred place of death & $34(13.7)$ \\
\hline Other ${ }^{b}$ & $22(8.8)$ \\
\hline \multicolumn{2}{|l|}{ Disposition from initial clinic appointment } \\
\hline Admit to palliative care unit & $58(23.3)$ \\
\hline New referral to community palliative care & $34(13.7)$ \\
\hline
\end{tabular}

Considering the totality of care required across the physical, social and psycho-existential domains, more comprehensive evaluation methods to ascertain the benefits of ambulatory palliative care are needed. The results of this study will inform the development of a phase II study examining the feasibility and acceptability amongst patients and clinicians on the use of electronic capturing of more comprehensive patientreported outcomes in the ambulatory cancer setting.

\section{Abbreviations}

ESAS: Edmonton Symptom Assessment Scale; NRS: Numerical Rating Scale; QOL: Quality Of Life; SAS: Symptom Assessment Scale; SCC: Supportive Care Clinic.

\section{Acknowledgements}

The authors thank Professor David Kissane and Katrina Ngo for their assistance with this study.

\section{Authors' contributions}

All authors contributed to the study conception and the final manuscript. Data collection was performed by RS, HT and AM, with verification and quality control checked by MS and NM. Statistical analysis was performed by ENG and ZA. The author(s) read and approved the final manuscript.

Funding

This study was funded by a Quality Improvement Research Grant from the Cabrini Foundation.

\section{Availability of data and materials}

The datasets generated and/or analysed during the current study are not publicly available due to organizational requirements for release but are available from the corresponding author on reasonable request.

\section{Declarations}

\section{Ethics approval and consent to participate}

This study has been performed in accordance with Declaration of Helsinki and ethics approval was obtained from Cabrini Health's Human Research Ethics Committee (Number: 08-18-05-20). The ethics committee waived the requirement for informed consent.

\section{Consent for publication}

Not applicable.

\section{Competing interests}

The authors declare they have no competing interests.

\section{Author details}

${ }^{1}$ Supportive, Psychosocial and Palliative Care Research Department, Cabrini Health, 154 Wattletree Road, Malvern, VIC 3144, Australia. ${ }^{2}$ School of Medicine, Sydney Campus, University of Notre Dame Australia, Sydney, NSW, Australia. ${ }^{3}$ Faculty of Medicine, Nursing and Health Sciences, Monash University, Melbourne, VIC, Australia.

Received: 8 November 2021 Accepted: 24 February 2022

Published online: 04 March 2022

\section{References}

1. Deshields TL, Potter P, Olsen S, Liu J. The persistence of symptom burden: symptom experience and quality of life of cancer patients across one year. Support Care Cancer. 2014;22:1089-96.

2. Kruger S, Ilmer M, Kobold S, Cadilha BL, Endres S, Ormanns S, et al. Advances in cancer immunotherapy 2019 - Latest trends. J Exp Clin Cancer Res. 2019;38:268.

3. Aktas A. Cancer symptom clusters: current concepts and controversies. Curr Opin Support Palliat Care. 2013;7:38-44.

4. Kang JH, Kwon JH, Hui D, Yennurajalingam S, Bruera E. Changes in symptom intensity among cancer patients receiving outpatient palliative care. J Pain Symptom Manag. 2013:46:652-60.

5. Shamieh O, Khamash O, Khraisat M, Jbouri O, Awni M, Al-Hawamdeh A, et al. Impact of outpatient palliative care (PC) on symptom burden in patients with advanced cancer at a tertiary cancer center in Jordan. Support Care Cancer. 2017:25:177-83.

6. Manitta V, Zordan R, Cole-Sinclair M, Nandurkar H, Philip J. The symptom burden of patients with hematological malignancy: a cross-sectional observational study. J Pain Symptom Manag. 2011;42:432-42. 
7. Zimmermann C, Swami N, Krzyzanowska M, Hannon B, Leighl N, Oza A, et al. Early palliative care for patients with advanced cancer: a clusterrandomised controlled trial. Lancet. 2014;383:1721-30.

8. Dalgaard KM, Bergenholtz H, Nielsen ME, Timm H. Early integration of palliative care in hospitals: a systematic review on methods, barriers, and outcome. Palliat Support Care. 2014;12:495-513.

9. Hannon B, Swami N, Pope A, Rodin G, Dougherty E, Mak E, et al. The oncology palliative care clinic at the Princess Margaret Cancer Centre: an early intervention model for patients with advanced cancer. Support Care Cancer. 2015;23:1073-80.

10. Rabow M, Kvale E, Barbour L, Cassel JB, Cohen S, Jackson V, et al. Moving upstream: a review of the evidence of the impact of outpatient palliative care. J Palliat Med. 2013;16:1540-9.

11. Follwell M, Burman D, Le LW, Wakimoto K, Seccareccia D, Bryson J, et al. Phase II study of an outpatient palliative care intervention in patients with metastatic cancer. J Clin Oncol. 2009;27:206-13.

12. Organization WH. WHO definition of palliative care. 2002. Geneva: World Health Organization; 2011. p. 1-2. http://www.who.int/cancer/palliative/ definition/en/\#. Accessed 4 Mar 2020

13. Palliative Care Service Development Guidelines - Palliative Care. https:// palliativecare.org.au/quality. Accessed 3 Nov 2021.

14. Hui D, Meng Y, Bruera S, Geng Y, Hutchins R, Mori M, et al. Referral criteria for outpatient palliative Cancer care: a systematic review. Oncologist. 2016;21:895-901.

15. Hui D, Mori M, Meng YC, Watanabe SM, Caraceni A, Strasser F, et al. Automatic referral to standardize palliative care access: an international Delphi survey. Support Care Cancer. 2018:26:175-80.

16. Bruera E, Kuehn N, Miller MJ, Selmser P, Macmillan K. The Edmonton symptom assessment system (ESAS): a simple method for the assessment of palliative care patients. J Palliat Care. 1991;7:6-9.

17. Carvajal A, Centeno C, Watson R, Bruera E. A comprehensive study of psychometric properties of the Edmonton symptom assessment system (ESAS) in Spanish advanced cancer patients. Eur J Cancer. 2011;47:1863-72.

18. Hui D, Bruera E. The Edmonton symptom assessment system 25 years later: past, present, and future developments. J Pain Symptom Manag. 2017;53:630-43.

19. Hannon B, Dyck M, Pope A, Swami N, Banerjee S, Mak E, et al. Modified Edmonton symptom assessment system including constipation and sleep: validation in outpatients with Cancer. J Pain Symptom Manag. 2015;49:945-52.

20. Yennurajalingam S, Kang JH, Hui D, Kang DH, Kim SH, Bruera E. Clinical response to an outpatient palliative care consultation in patients with advanced cancer and cancer pain. J Pain Symptom Manag. 2012:44:340-50

21. Aoun SM, Monterosso L, Kristjanson LJ, McConigley R. Measuring symptom distress in palliative care: psychometric properties of the symptom assessment scale (SAS). J Palliat Med. 2011;14:315-21.

22. MBS online - MBS Online. http://www.mbsonline.gov.au/internet/mbson line/publishing.nsf/Content/Home. Accessed 6 Mar 2021

23. Eagar K, Watters P, Currow DC, Aoun SM, Yates P. The Australian palliative care outcomes collaboration (PCOC) measuring the quality and outcomes of palliative care on a routine basis. Aust Health Rev. 2010;34:186-92

24. Hui D, Shamieh O, Paiva CE, Khamash O, Perez-Cruz PE, Kwon JH, et al. Minimal clinically important difference in the physical, emotional, and Total symptom distress scores of the Edmonton symptom assessment system. J Pain Symptom Manag. 2016;51:262-9.

25. Farrar JT, Young JP, LaMoreaux L, Werth JL, Poole RM. Clinical importance of changes in chronic pain intensity measured on an 11-point numerical pain rating scale. Pain. 2001;94:149-58.

26. Ferrell BR, Temel JS, Temin S, Alesi ER, Balboni TA, Basch EM, et al. Integration of palliative care into standard oncology care: American society of clinical oncology clinical practice guideline update. J Clin Oncol. 2017;35:96-112.

27. Smith CB, Phillips T, Smith TJ. Using the new ASCO clinical practice guideline for palliative care concurrent with oncology care using the TEAM approach. Am Soc Clin Oncol Educ Book. 2017;37:714-23.

28. Rosenwax L, Spilsbury K, McNamara BA, Semmens JB. A retrospective population based cohort study of access to specialist palliative care in the last year of life: who is still missing out a decade on? BMC Palliat Care. 2016;15:46.

29. Michael N, O'Callaghan C, Brooker JE, Walker H, Hiscock R, Phillips D. Introducing a model incorporating early integration of specialist palliative care: a qualitative research study of staff's perspectives. Palliat Med. 2016;30:303-12.

30. Lefkowits C, Rabow MW, Sherman AE, Kiet TK, Ruskin R, Chan JK, et al. Predictors of high symptom burden in gynecologic oncology outpatients: who should be referred to outpatient palliative care? Gynecol Oncol. 2014;132:698-702.

31. Kenne Sarenmalm E, Browall M, Gaston-Johansson F. Symptom burden clusters: a challenge for targeted symptom management. A longitudinal study examining symptom burden clusters in breast cancer. J Pain Symptom Manag. 2014;47:731-41.

\section{Publisher's Note}

Springer Nature remains neutral with regard to jurisdictional claims in published maps and institutional affiliations.
Ready to submit your research? Choose BMC and benefit from:

- fast, convenient online submission

- thorough peer review by experienced researchers in your field

- rapid publication on acceptance

- support for research data, including large and complex data types

- gold Open Access which fosters wider collaboration and increased citations

- maximum visibility for your research: over $100 \mathrm{M}$ website views per year

At BMC, research is always in progress.

Learn more biomedcentral.com/submissions 